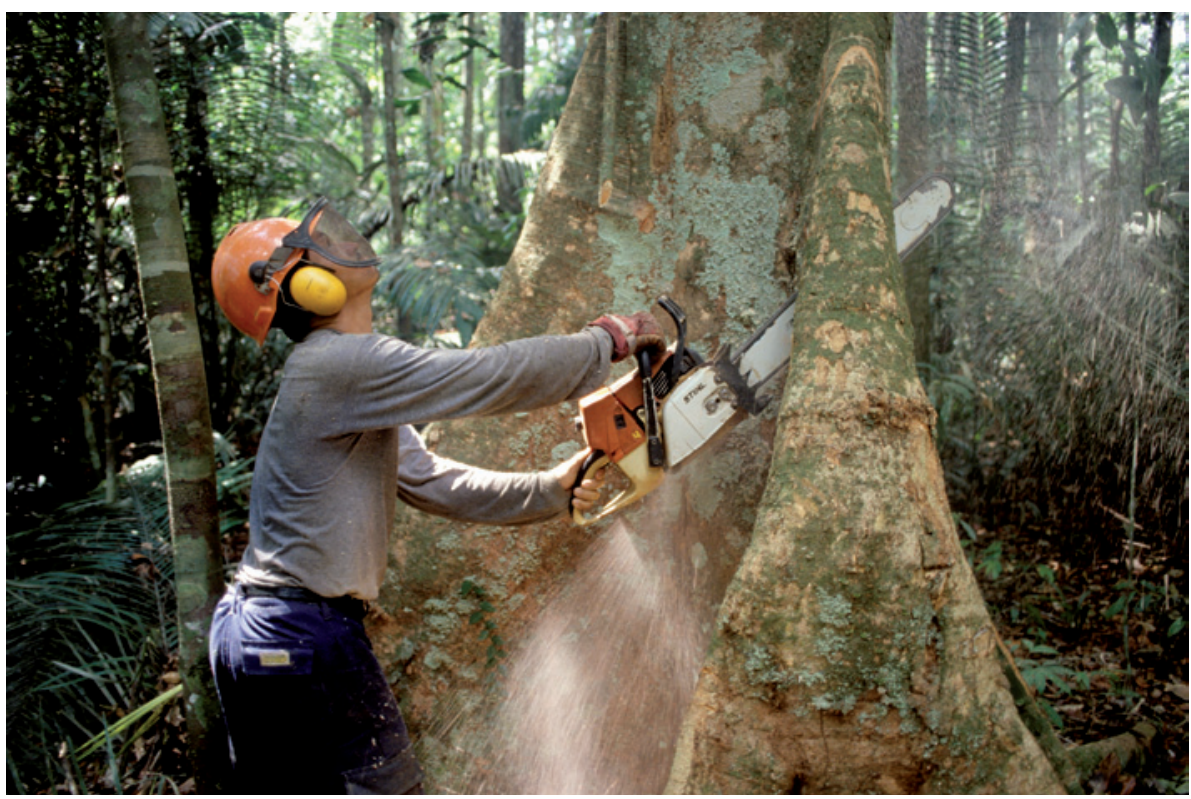

Brazilian scientists are trying to understand the effects of logging on carbon emissions in the Amazon.

DEFORESTATION

\title{
Brazil unveils tool to track emissions
}

\section{Carbon releases lag behind Amazon deforestation.}

\section{BY JEFF TOLLEFSON}

$\mathrm{T}$ he rate of deforestation in the Brazilian Amazon has plummeted by $77 \%$ in the past seven years, but annual carbon emissions associated with deforestation have not fallen nearly as much, says a Brazilian study that combines satellite data and biomass maps to model the change. The difference is in large part due to a natural lag as carbon stocks slowly decay and make their way into the atmosphere as carbon dioxide.

Brazil has long had a sophisticated satellitebased system for monitoring deforestation, but translating forest clearance into emissions has remained a challenge. The picture is more complex than often assumed. The area cleared each year decreased from 27,772 square kilometres - a swathe the size of Sicily — in 2004 to 6,418 square kilometres in 2011. A direct conversion of that lost biomass into carbon would suggest a drop in annual carbon dioxide emissions from more than 1.1 billion tonnes of $\mathrm{CO}_{2}$ in 2004 to 298 million tonnes of $\mathrm{CO}_{2}-\mathrm{a}$ reduction of nearly $74 \%$.

But numbers calculated by Brazil's National Institute for Space Research (INPE) in Sao Jose dos Campos using the new model, and released on 13 August, suggest a reduction of only $57 \%$ in actual emissions, with the difference due to factors such as the time it takes for roots to decay, and the fact that forest debris cut in one year might be burned in another (see 'Carbon lag'). A paper describing the model was published last

\section{CARBON LAG}

Curbing Amazon deforestation has cut greenhouse-gas emissions, but the time it takes for wood and roots to decay delays the pay-off by a few years.

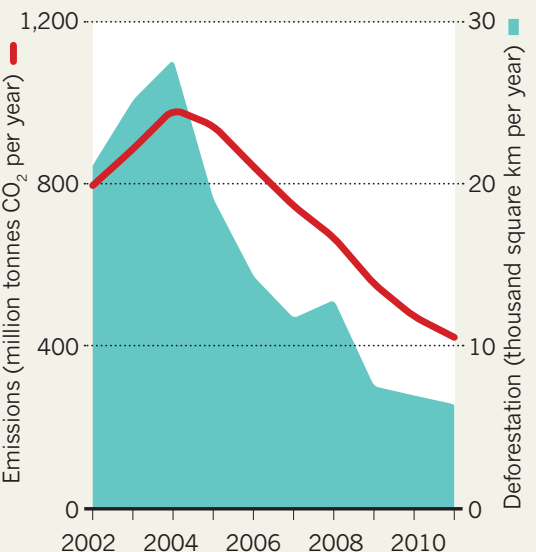

$200220042006 \quad 2008 \quad 2010$ week (A. P. D. Aguiar et al. Global Change Biology http://doi.org/h7g; 2012).

"We don't know how the government is going to use this information at this point but what we are trying to express is that this is a more correct way to understand carbon emissions," says Jean Ometto, a researcher at INPE who helped to develop the system. $\mathrm{He}$ estimates that efforts to forestall deforestation in the Amazon have lowered Brazil's overall carbon emissions by roughly $17 \%$ since 2004 .

The model is a milepost for scientists and policy-makers working at the intersection of forestry, agriculture and global warming. Many scientists are busy linking satellite measurements to field and aerial studies to create more accurate maps of forest biomass, which can then be used to calculate emissions. INPE's new model carries that work forward, allowing Brazilian scientists to provide annual estimates of both deforestation and carbon emissions, and setting the stage for a deeper analysis of the impacts of logging, agriculture and forest regrowth.

Richard Houghton, a forestry expert at the Woods Hole Research Center in Falmouth, Massachusetts, says that the actual results are not necessarily surprising. But he credits INPE with developing a solid emissions model that will help Brazil build on its forest-monitoring system and tackle emissions in a serious way. "That's where you'd like the rest of the world to be, where Brazil is."

INPE's analysis confirms earlier findings that deforestation is gradually moving into denser forests, which means that emissions per hectare are increasing. The results also suggest that forest regrowth has had little impact on net emissions because many secondary forests are periodically chopped down. INPE scientists say that secondary forests could have a significant impact on net emissions if allowed to regrow.

One question about the model is how to represent emissions due to logging. INPE scientists assume that some logging has already taken place in clear-cut areas, but they are still working on ways to account for broader timber operations. Earlier research suggests that fully accounting for logging could roughly double overall emissions from the Amazon (G. P. Asner Science 310, 480-482; 2005).

And Sandra Brown, a forestry expert at the non-profit organization Winrock International, based in Arlington, Virginia, asks whether it makes sense to highlight the time lags involved in emissions, which could increase public uncertainty and run the risk of confusing policy-makers. At the same time, she says, scientists do need to better understand the way carbon is cycling through forests. And she says the next major challenge is for INPE to build the effects of widespread logging operations into its emissions model.

“They've got the equipment, and they've got the know-how, and they've got the resources to do it," she says. — 